\title{
COMUNICAÇÃO
}

\section{COMPONENTES DE PRODUÇÃO DO MILHO EM DIFERENTES ÉPOCAS DE ADUBAÇÃO NITROGENADA EM COBERTURA NOS SISTEMAS DE PLANTIO CONVENCIONAL E DIRETO}

\author{
CÍCERO MONTI TEIXEIRA ${ }^{1}$ \\ GABRIEL JOSÉ DE CARVALHO ${ }^{2}$
}

\begin{abstract}
RESUMO - Objetivou-se com este trabalho avaliar os componentes de produção do Milho cultivado no sistema convencional e no plantio direto sob palhada de Aveia preta (Avena strigosa Sereb), em diferentes épocas de adubação nitrogenada em cobertura. A aveia preta produziu em média 6,37 t.ha $^{-1}$ de matéria seca. Não houve diferença significativa entre as épocas de adubação de cobertura e sistema de plantio para as variáveis
\end{abstract}

estande final, altura de planta, altura de espiga, espigas por planta, plantas quebradas e acamadas e produtividade. O florescimento feminino foi mais precoce no plantio convencional, pelo fato de a emergência das plantas ser mais rápida que no plantio direto. $\mathrm{O}$ tempo de florescimento feminino para plantio convencional e plantio direto foi, em média, de 74 e 76 dias, respectivamente.

TERMOS PARA INDEXAÇÃO: Plantio direto, milho, adubação nitrogenada de cobertura.

\section{MAIZE PRODUCTION COMPONENTS IN DIFFERENT EPOCHS OF NITROGEN FERTILIZATION IN COVERTURE IN THE CONVENTIONAL AND NO-TILL SYSTEMS}

\begin{abstract}
The objective of this work was to evaluate the maize production components in conventional and in no-till systems, under the straw of black oat (Avena strigosa Sereb), after different epochs of $\mathrm{N}$ fertilization in coverture. The black oat produced $6,37 \mathrm{t} \mathrm{ha}^{-1}$ of straw. It was not verified significant difference between the epochs of fertilization and
\end{abstract}

plantation systems for the characteristics: stand, plant height, ear height, number of ears per plant, broken and fallen plants and productivity. The female flowering was faster in the conventional than in no-till system, because plant emergency is quicker than in no-till. The time of female flowering for conventional and for notillage system was 74 and 76 days, respectively.

INDEX TERMS: No-tillage, corn, nitrogen fertilizer in coverture.

O plantio direto é, desde a década de 70, quando foi introduzido no Brasil, um método racional de exploração do solo, protegendo-o do impacto das gotas de chuva, aumentando a infiltração, a ciclagem de nutrientes, aumentando ou mantendo o teor de matéria orgânica, e principalmente diminuindo a erosão. De acordo com Denardin (1980), o impacto direto das gotas de chuva é responsável por $95 \%$ da erosão hídrica. Além desse benefício, Sá (1993) cita que no sistema de plantio direto o acúmulo de material orgânico na superfície do solo proporciona um aumento da atividade biológica, transformando os resíduos das culturas em "húmus" e liberando nutrientes em formas solúveis para a absorção das plantas. No entanto, Vale et al. (19--?) ressaltam que os microorganismos podem promover imobilização de nitrogênio inorgânico, concorrendo com as plantas na absorção desse nutriente.

\footnotetext{
1. Engenheiro Agrônomo - Mestrando em Fitotecnia da UNIVERSIDADE FEDERAL DE LAVRAS, Caixa Postal 37 37200-000 Lavras, MG - Bolsista do CNPq.

2. Engenheiro Agrônomo - DSc, Professor Adjunto III da UFLA.
} 
Segundo Victoria et al. (1992), a adição de quantidades elevadas de resíduos culturais com alta relação carbono/nitrogênio $(\mathrm{C} / \mathrm{N})$ proporciona aos microorganismos quimioorganotróficos, que atuam na decomposição da matéria orgânica, uma multiplicação gradativa, produzindo $\mathrm{CO}_{2}$ em grandes quantidades. Nessas condições, o nitrato praticamente desaparece do solo e o mesmo deve ocorrer com o amônio, se presente. Dessa forma, durante um certo período, a cultura terá pouca ou nenhuma disponibilidade de nitrogênio mineral para o seu desenvolvimento. Entretanto, a continuidade do processo de decomposição diminui a relação $\mathrm{C} / \mathrm{N}$ da palhada, uma vez que o carbono está sendo perdido na forma de $\mathrm{CO}_{2}$ e o nitrogênio sendo conservado pela formação de massa celular microbiana. Segundo o mesmo autor, essa situação continua até que os resíduos vegetais atinjam uma relação $\mathrm{C} / \mathrm{N}$ em torno de 20 . Nesse ponto, a atividade dos microorganismos decompositores e a formação de $\mathrm{CO}_{2}$ diminuem gradualmente pela falta de carbono facilmente oxidável e o nitrogênio deixa de ser limitante para os processos microbianos, passando a ocorrer a liberação de N - mineral. Assim, a nitrificação volta a ser ativa, produzindo nitrato em níveis superiores às condições originais.

Para Lopes (1996), o momento mais adequado para proceder à adubação nitrogenada em cobertura é variável em função de fatores como a cultura, tipo de solo, quantidade e intensidade de chuvas, dentre outros, e em cultivos com incorporação de palhada com alta relação C / N, pode haver a necessidade de antecipar a cobertura nitrogenada. Assim, uma cobertura com nitrogênio no momento correto é um importante fator para o aumento da produção.

Além do aumento da dose de nitrogênio na semeadura do milho, em sistemas de semeadura direta em sucessão a gramíneas, estratégias de manejo têm sido preconizadas com a finalidade de diminuir o efeito negativo provocado pelos restos culturais. Dentre essas estratégias, destacam-se o atraso da época de semeadura do milho, após a dessecação da aveia preta, e a aplicação de $\mathrm{N}$ nos estádios iniciais de desenvolvimento e na floração da mesma, ou seja, em pré-semeadura do milho (Argenta \& Silva, 1999).

Segundo Sá (1993), quando se disponibiliza nitrogênio na fase inicial de desenvolvimento do milho cultivado sob palhada de aveia, esse apresenta desenvolvimento semelhante ao do seu cultivo sob palhada de leguminosas, como a ervilhaca.

Objetivou-se com este trabalho avaliar os componentes de produção do milho cultivado no sistema de plantio convencional e direto sob palhada de aveia preta
(Avena strigosa Sereb), em diferentes épocas de adubação nitrogenada em cobertura.

O trabalho constituiu-se de duas fases e foi instalado no campus da Universidade Federal de Lavras. A primeira fase foi implantada em junho de 2000, quando foi plantada a aveia preta no sistema convencional (aração e gradagem), sem adubação e com irrigação. Quando a aveia se encontrava com $50 \%$ de floração, foram retiradas quatro amostras de $1 \mathrm{~m}^{2}$ para determinação da massa verde e matéria seca.

A segunda fase foi instalada em setembro de 2000, sendo o plantio direto do milho sob a palhada de aveia e o plantio convencional com o solo arado e gradeado em área de pousio de inverno.

$\mathrm{O}$ delineamento utilizado na segunda fase foi de blocos casualizados, com 3 repetições, em esquema fatorial $4 \times 2$, e um dos fatores foi constituído pela adubação de cobertura, na dosagem de $220 \mathrm{~kg} \cdot \mathrm{ha}^{-1}$ de uréia $\left(100 \mathrm{~kg} \cdot \mathrm{ha}^{-1}\right.$ de $\left.\mathrm{N}\right)$ em quatro níveis: no plantio $(24 \mathrm{~kg}$ na base do plantio $+100 \mathrm{~kg}$ equivalente à cobertura), $100 \mathrm{~kg}$ de $\mathrm{N}$ aos dez, vinte e trinta dias após a emergência da cultura. No plantio, utilizaram-se como adubação de base $300 \mathrm{~kg} \cdot \mathrm{ha}^{-1}$ de NPK na formulação 8-28-16. O segundo fator foi constituído pelos sistemas de cultivo plantio direto e convencional. As diferentes épocas foram distribuídas nas parcelas e os sistemas de cultivo, nas faixas. As parcelas foram compostas por quatro linhas de $5 \mathrm{~m}$ de comprimento, e as linhas laterais e $1 \mathrm{~m}$ de cada extremidade foram considerados bordaduras.

Foram feitas as seguintes avaliações: stand inicial, em que foram contadas todas as plantas da área útil de cada parcela aproximadamente 15 dias após a germinação; stand final, à época da colheita, contaram-se novamente as plantas da área útil de cada parcela; altura de plantas, às vésperas da colheita, mediram-se cinco plantas aleatoriamente na área útil de cada parcela. As medições foram feitas do nível do solo à folha bandeira; número de espigas, antes da colheita contaram-se todas as espigas da área útil de cada parcela; produtividade, após a colheita, pesaram-se todos os grãos da área útil, corrigindo-se para $13 \%$ de umidade; a altura de espiga, foi determinada através da medição da superfície do solo à inserção da primeira espiga; o florescimento feminino foi determinado pelo número de dias da emergência das plantas, até quando $50 \%$ dessas apresentaram espigas com estilo-estigmas visíveis; prolificidade, foi determinada a relação existente entre o número de espigas e o número total de plantas da parcela; plantas acamadas e quebradas foram determinadas pela contagem das plantas quebradas abaixo da espiga, mais as plantas 
acamadas com um ângulo menor ou igual a $30^{\circ}$ com a superfície do solo.

A aveia preta produziu, em média, 6,37 t.ha ${ }^{-1}$ de matéria seca. Esse resultado foi superior aos encontrados por Teixeira \& Carvalho (1999) e Caixeta \& Carvalho (1999). Isso provavelmente ocorreu em razão de a época de plantio ter sido em junho, o que foi diferente dos trabalhos desses autores, nos quais a cultura foi exposta a períodos de temperaturas mais elevadas e dias mais longos. Quanto ao milho, observando-se a análise de variância (Tabela 1), nota-se que apenas a variável florescimento feminino apresentou diferença significativa para o fator sistema de plantio, sendo mais precoce no plantio convencional (Tabela 2). Esse resultado pode estar relacionado ao fato de que a emergência das plantas foi mais rápida no plantio convencional que no direto, por causa da ausência de impedimento físico da cobertura morta, fazendo com que essas alcancem o número de horas de luz necessário para o florescimento mais cedo. O tempo de florescimento feminino para plantio convencional e direto foi de 74 e 76 dias, respectivamente. $\mathrm{O}$ fato de não ter ocorrido diferenças significativas para os componentes de produção do milho nas diferentes épocas de adubação de cobertura no plantio direto possivelmente se deve à baixa relação C/N da aveia no estádio de floração (Monegat, 1991), o que faz com que a imobilização de nitrogênio seja menor.

Com o experimento, pode-se concluir que o milho quando cultivado no sistema convencional emerge do solo mais cedo (2 dias), devido à ausência do impedimento físico da palhada, florescendo mais precocemente que no sistema plantio direto. Usando-se a aveia preta como cobertura morta, manejada na floração, a imobilização de nitrogênio talvez tenha sido menor devido à baixa relação $\mathrm{C} / \mathrm{N}$ da palhada formada, não competindo com a cultura a ponto de causar deficiência e queda na produtividade.

TABELA 1 - Resumo da Análise de variância dos componentes de produção do milho cultivado no sistema convencional de plantio e no plantio direto sob palhada de aveia preta. UFLA Lavras - MG - 2001.

\begin{tabular}{lcccccccc}
\hline & & \multicolumn{7}{c}{ Quadrado Médio } \\
\cline { 3 - 9 } C. V. & G. L. & Estande** & Flor. F** & Alt. Plant. & Alt. Espig. & Prolif. & Queb. Acam.** & Produt. \\
\hline Tratam. & 3 & 0,1487 & 0,0028 & 0,0090 & 0,0097 & 0,0162 & 0,0438 & 3,2737 \\
Blocos & 2 & 0,0303 & 0,0384 & 0,0260 & 0,0053 & 0,1107 & $0,2134^{*}$ & 7,0014 \\
Erro A & 6 & 0,1944 & 0,0130 & 0,0249 & 0,0180 & 0,0377 & 0,0147 & 2,4871 \\
Faixas & 1 & 0,0042 & $0,0729 *$ & 0,1873 & 0,1335 & 0,0888 & 0,0100 & 71,8607 \\
Erro B & 2 & 0,1188 & 0,0009 & 0,0356 & 0,0195 & 0,1530 & 0,3901 & 5,3294 \\
Tr*Faix & 3 & 0,2415 & 0,0101 & 0,0442 & 0,0098 & 0,2338 & 0,0353 & 0,7431 \\
Erro C & 6 & 0,1142 & 0,0104 & 0,0211 & 0,0151 & 0,1356 & 0,0501 & 1,8462 \\
\hline C.V. 1 (\%) & & 10,85 & 1,31 & 8,4 & 14,16 & 14,84 & 10,16 & 22,15 \\
C.V. 2 (\%) & & 8,48 & 0,35 & 10,04 & 14,76 & 29,88 & 52,36 & 32,42 \\
C.V. 3 (\%) & & 8,31 & 1,17 & 7,71 & 12,97 & 28,12 & 18,76 & 19,08 \\
\hline
\end{tabular}

* Significativo no teste de $\mathbf{F}$ a $5 \%$ de significância.

** Dados transformados para raiz quadrada de $\mathrm{x}+1$.

Ciênc. agrotec., Lavras. V.27, n.1, p.228-231, jan./fev., 2003 
TABELA 2 - Florescimento feminino do híbrido de milho Cargill-747 nos sistemas de plantio convencional e direto sob palhada de aveia preta. UFLA Lavras - MG $-2001$

\begin{tabular}{cc}
\hline Sistemas & $\begin{array}{c}\text { Floresc. Femin. } \\
\text { (Dias) }\end{array}$ \\
\hline Plantio Direto & $76 \mathrm{a}$ \\
Plantio Convencional & $74 \mathrm{~b}$
\end{tabular}

As médias seguidas de mesma letra, nas colunas, não diferem entre si no teste de Tukey $5 \%$ de significância.

\section{REFERÊNCIAS BIBLIOGRÁFICAS}

ARGENTA, G.; SILVA, P. R. F. Adubação nitrogenada em milho implantado em semeadura direta após a aveia preta. Ciência Rural, Santa Maria, v. 29, n. 4, p. 745-754, 1999.

CAIXETA, C. C.; CARvalHO, G. J. de. Avaliação de diferentes espécies de gramíneas para produção de matéria seca no sistema de cultivo plantio direto com e sem adubação cultivadas no verão e no inverno. In: CONGRESSO DE INICIAÇÃO CIENTÍFICA DA UFLA, 12., 1999, Lavras. Anais... Lavras: UFLA, 1999. p. 85 .
DENARDIN, J. E.; WUNSCHE, W. A. Conservação e manejo dos solos; Planalto Rio -Grandense, considerações gerais. Passo Fundo: EMBRAPA-CNPT, 1980. $170 \mathrm{p}$.

LOPES, A. S. Guia das melhores técnicas agrícolas. São Paulo: ANDA, 1996. 28 p.

MONEGAT, C. Plantas de cobertura do solo: características e manejo em pequenas propriedades. Chapecó, 1991. 337 p.

SÁ, J. C. de M. Manejo da fertilidade do solo no plantio direto. Castro: Fundação ABC, 1993. 96 p.

TEIXEIRA, C. M.; CARVALHO, G. J. de. Estudo do comportamento do sorgo, milheto e aveia preta na produção de forragem e matéria seca para cobertura morta do solo no sistema plantio direto. In: CONGRESSO DE INICIAÇÃO CIENTÍFICA DA UFLA, 12., 1999, Lavras. Anais... Lavras: UFLA, 1999. p. 44.

VALE, F. R.; GUILHERME, L. R. G.; GUEDES, G. A. A.; FURTINI NETO, A. E. Fertilidade do Solo: dinâmica e disponibilidade de nutrientes. Lavras: UFLA/FAEPE, 19--? 171 p.

VICTORIA, R. L.; PICCOLO, M. C.; VARGAS, A. A. T. O ciclo do nitrogênio. In: CARDOSO, E. J. B. N.; TSAI, S. M.; NEVES, M. C. P. Microbiologia do solo. Campinas: SBCS, 1992. p. 19. 